\title{
Haemodynamic deterioration after treatment with adenosine
}

\author{
Richard P W Cowell, Vincent E Paul, Charles D J Ilsley
}

\begin{abstract}
A 26 year old woman presented with a narrow complex tachycardia with a rate of 210 beats/min. Adenosine converted this to atrial fibrillation with a rate of 280 beats/min with associated haemodynamic deterioration that needed electrical cardioversion.
\end{abstract}

(Br Heart f 1994;71:569-571)

Adenosine is now the first line treatment for narrow complex tachycardias. ${ }^{1}$ It has largely replaced verapamil, which may accelerate preexcited atrial fibrillation and depress ventricular function. ${ }^{2}$ Adenosine is considered to be a relatively safe drug with a short half life and a low incidence of proarrhythmia. It is used both therapeutically and in the diagnosis of arrhythmias of unknown origin. ${ }^{3}$ We describe a case in which adenosine converted a narrow complex tachycardia to rapid pre-excited atrial fibrillation and resulted in considerable haemodynamic deterioration.

\section{Case report}

A 26 year old woman presented to the accident and emergency department of the referring hospital with sustained palpitation for one and a half hours. She had had palpitation for several years. There was no family history and she did not take any medication. On arrival at the casualty department she was haemodynamically stable with a blood pressure of $140 / 80 \mathrm{~mm} \mathrm{Hg}$. An electrocardiogram showed a regular narrow complex tachycardia with a rate of 210 beats/min (fig 1). Carotid sinus massage had no effect. An intravenous bolus of $3 \mathrm{mg}$ of adenosine ended the tachycardia but within three beats this was replaced by an irregular broad complex tachycardia with a ventricular rate of 280 beats $/ \mathrm{min}$. The configuration was suggestive of pre-excited

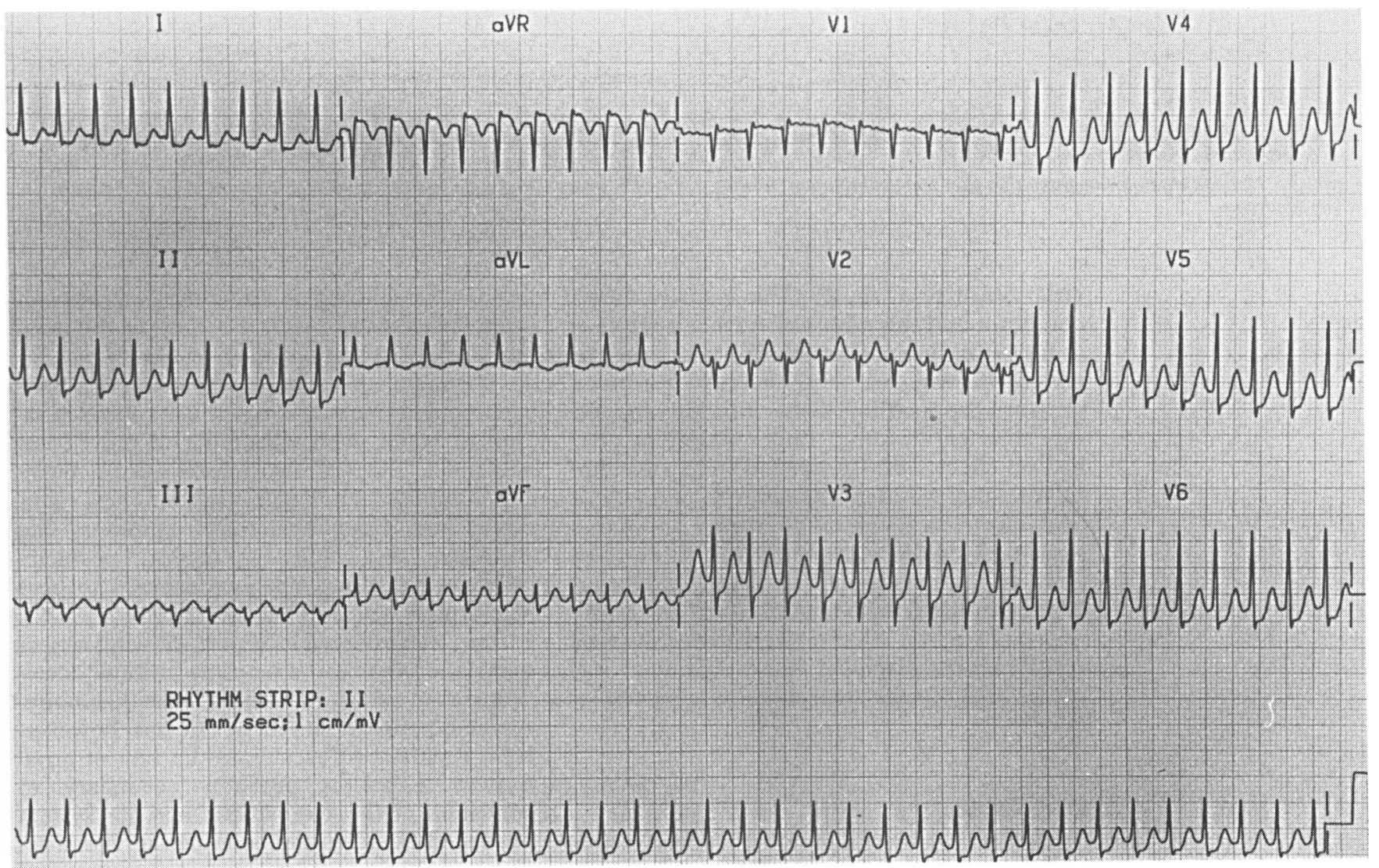

Figure 112 Lead electrocardiogram on admission showing a regular narrow complex tachycardia. 


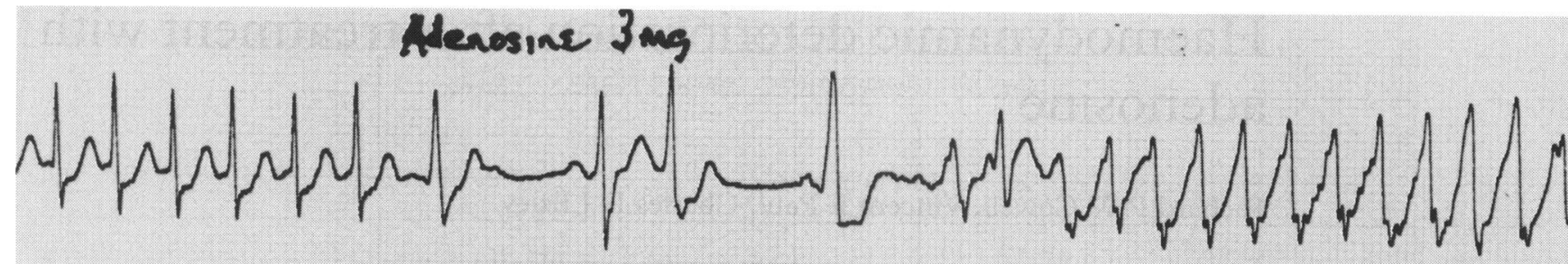
Figure 2 Electrocardiogram recorded when adenosine was given showing end of the tachycardia for three beats then an irregular broad complex
tachycardia (pre-excited atrial fibrillation).

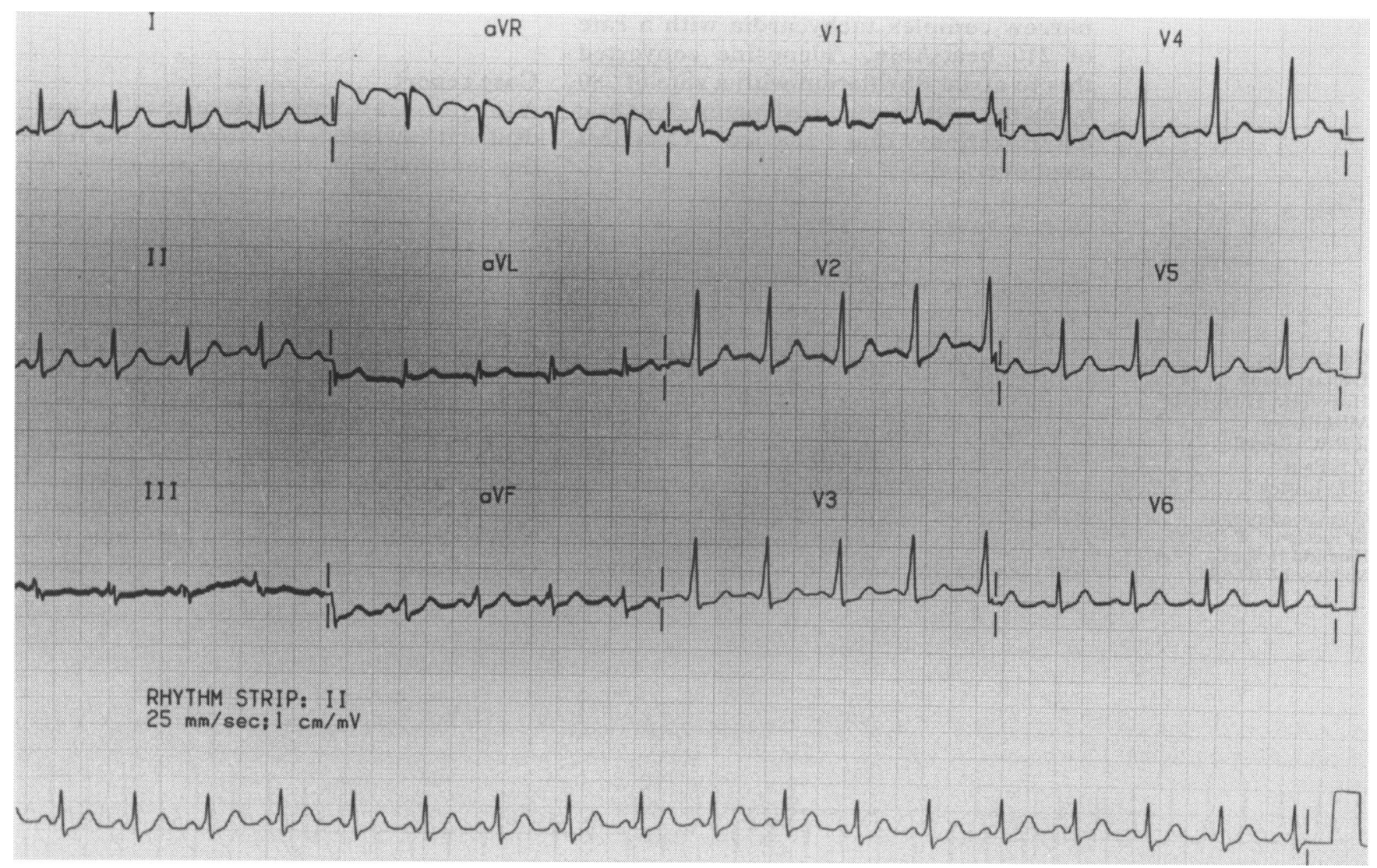

Figure 312 Lead electrocardiogram after electrical defibrillation showing a short PR interval and delta was waves compatible with Wolf-ParkinsonWhite syndrome.

atrial fibrillation (fig 2). The casualty officer could not end this with two further boluses of 6 and $9 \mathrm{mg}$ adenosine. During this time the patient became pale and clammy, her blood pressure dropped to $100 / 60 \mathrm{~mm} \mathrm{Hg}$, and she was thus cardioverted under sedation. $50 \mathrm{~J}$ had no effect; $100 \mathrm{~J}$ produced ventricular fibrillation that was defibrillated with $300 \mathrm{~J}$. A 12 lead electrocardiogram after this showed a sinus tachycardia with a short PR interval and delta waves consistent with Wolff-ParkinsonWhite syndrome with a left free wall accessory pathway (fig 3). Electrophysiological studies confirmed the diagnosis and the pathway was successfully treated with radiofrequency ablation.

\section{Discussion}

Adenosine has been found to be equally effective $^{4}$ or more effective ${ }^{5}$ than verapamil at ending induced junctional tachycardia and has become established as a first line treatment for such arrhythmias. Also, it is used in the diagnosis of broad complex tachycardia. ${ }^{3}$

The main advantage of adenosine as a therapeutic and diagnostic agent is its short duration of action with a half life of only a few seconds. ${ }^{67}$ Side effects including facial flushing, dyspnoea, choking sensation, chest tightness, and bradycardia are common but transient and rarely a clinical problem. Adenosine is thus widely considered to be a safe drug.

There is no previous report showing a clear correlation between adenosine and the development of atrial fibrillation with haemodynamic deterioration. Adenosine has, however, been reported to accelerate the rate of atrial flutter. ${ }^{89}$ This is probably secondary to activation of the sympathetic nervous syst $\mathrm{Em}$ produced by adenosine stimulating chemoreceptors in the carotid body. ${ }^{10}$

In this case, adenosine produced rapid 
atrial fibrillation immediately after a transient reduction in heart rate. The likely mechanism for this was a reduction in the atrial refractory period, which has been shown to occur in humans. ${ }^{11}$ Although the same group showed that pacing induced atrial fibrillation was facilitated by adenosine ${ }^{11}$ the clinical incidence is scant. In a multicentre trial comparing adenosine with verapamil three of the 208 patients treated with adenosine developed atrial flutter or fibrillation at $14 \mathrm{~min}, 90 \mathrm{~s}$, and $45 \mathrm{~s}$ after treatment. This incidence was not significantly different from the placebo group (two of 22) or the verapamil group (none of 58).

Pre-excited atrial fibrillation may result in ventricular fibrillation by rapid antegrade conduction along an accessory pathway. The usual treatment is direct current cardioversion and further adenosine was inappropriate in this case. With increasing use of adenosine this uncommon side effect may be seen more often and doctors should be aware of the possibility. This emphasises that resuscitation facilities should always be immediately available when adenosine is given.
1 Adenosine for acute cardiac arrhythmias. Drug Ther Bull 1993;31:49-50.

2 McGovern B, Garan H, Ruskin JN. Precipitation of cardiac arrest by verapamil in patients with WolffParkinson-White syndrome. Ann Intern Med 1986;104: 791-4.

3 Rankin AC, Oldroyd KG, Chong E, Rae AP, Cobbe SM Value and limitation of adenosine in the diagnosis and Value and limitation of adenosine in the diagnosis and
treatment of narrow and broad complex tachycardias. $\mathrm{Br}$ treatment of narrow and bre

4 Garratt CJ, Linker NJ, Griffith MJ, Ward DE, Camm AJ. Comparison of adenosine and verapamil for termination of paroxysmal junctional tachycardia. Am $\mathcal{f}$ Cardiol $1989 ; 64: 1310-6$.

5 DiMarco JP, Miles W, Akhtar M, et al. Adenosine for paroxysmal supraventricular tachycardia: dose ranging and comparison with verapamil. Ann Intern Med 1990; 113:104-10.

6 Moser GH, Schrader J, Deussen A. Turnover of adenosine in plasma of human and dog blood. Am $\mathcal{F}$ Physiol 1989; 256:C799-806.

7 Klabunde RE. Dipyridamole inhibition of adenosine metabolism in human blood. Eur $\mathcal{F}$ Pharmacol 1983;93: 21-6.

8 Rankin AC, Rae AP, Houston A. Acceleration of ventricular response to atrial flutter after intravenous adenosine. lar response to atrial flutter

9 Slade AKB, Garratt CJ. Proarrhythmic effect of adenosine in a patient with atrial flutter. Br Heart $\mathcal{F} 1993 ; 70: 91-2$.

10 Biaggoni I, Olafsson B, Robertson RM, Hollister AS, Robertson D. Cardiovascular and respiratory effects of adenosne in conscious man. Evidence for chemoreceptor activation. Circ Res 1987;61:779-86.

11 O'Nunain SO, Garratt C, Paul V, Debbas N, Ward D, Camm AJ. Effect of intravenous adenosine on human atrial and ventricular repolarisation. Cardiovasc Res 1992;26:939-43. 